\section{AB0333 USEFULNESS OF MULTI-PARAMETRIC EVALUATION INCLUDING MINOR SALIVARY GLAND BIOPSY FOR THE DIFFERENTIAL DIAGNOSIS OF SICCA SYNDROME IN A SPANISH SINGLE-CENTER EXPERIENCE}

J. Álvarez Troncoso ${ }^{1}$, C. M. Oñoro López ${ }^{1}$, C. Soto Abánades ${ }^{1}$, E. Ruiz Bravo ${ }^{2}$, L. Blasco Santana ${ }^{2}$, A. Noblejas Mozo ${ }^{1}$, E. Martínez Robles ${ }^{1}$, Á. Robles Marhuenda ${ }^{1}$, L. Ramos Ruperto ${ }^{1}$, J. J. Rios ${ }^{1}$, F. Arnalich Fernández ${ }^{1}{ }^{1}{ }^{H}$ Hospital Universitario La Paz, Internal Medicine, Madrid, Spain; ${ }^{2}$ Hospital Universitario La Paz, Pathology, Madrid, Spain

Background: Sjögren's syndrome (SS) is a systemic autoimmune disease characterized by mononuclear cell infiltration of the exocrine glands, which leads to sicca syndrome and systemic manifestations. The minor salivary gland biopsy (MSGB) is undoubtedly important for the classification, diagnosis and prognosis of SS. However, differentiating SS and non-Sjögren's sicca syndrome (NSS) can be challenging.

Objectives: The aim was to evaluate the histological characteristics of MSGB besides focus score (FS) in patients with sicca syndrome and the usefulness of the different clinical, serological and histological parameters to diagnose, classify and describe the prognosis of patients with Sjögren's syndrome.

Methods: Prospective observational single-center study of patients referred for study of sicca syndrome with multi-parametric evaluation from January 2019 to December 2020. A diagnostic protocol based on Schirmer's test, unstimulated whole salivary flow (UWSF) and minimally invasive MSGB was applied. Patients fulfilling 2016 ACR-EULAR classification criteria were classified as SS.

Results: In a cohort of 115 patients with sicca syndrome, 55 (47.8\%) were diagnosed with SS. The mean age was $56.9 \pm 14.5$ years and most of the patients were women $(81,7 \%)$ with no significant differences between SS and NSS. SS were more likely to present positive Schirmer's test, positive UWSF, anti-Ro+, $F S \geq 1$, antinuclear antibodies $(A N A+)$, rheumatoid factor $(R F+)$ and anti-La+ among others.

MSGB was a safe procedure and very effective (only $7 \%$ insufficient biopsies) in our cohort. The mean gland size of the MSGB was $5.7 \pm 0.37 \mathrm{~mm}^{2}$. Furthermore, it was the individual parameter that most correlated with SS, even more than anti-Ro+, Schirmer's and UWSF. Seronegative SS (Anti-Ro-) was 47.3\%. These patients could not have been diagnosed except by MSGB. Scintigraphy did not help to differentiate SS from NSS, neither patient-referred xerostomia nor xerophthalmia. The most frequent histological diagnosis was focal lymphocytic sialadenitis (FLS) $(81.8 \%)$ followed by nonspecific chronic sialadenitis $(9.1 \%)$. However, only FLS had a correlation with SS. There were no MSGBs labeled normal among the SS patients. Mean FS was $2.22 \pm 0.2(16.7 \%$ had FS $\geq 3)$.

The rest of the histological parameters that showed a positive correlation with SS were glandular atrophy (GA), germinal centers (GC), lymphoepithelial lesions (LEL) and lymphoid follicles (LF). FS $\geq 1$ is the current histological classification criteria for ACR/EULAR. However, the presence of lymphocytic infiltrates (LI) (although not $F S \geq 1$ ) and FLS were suggestive markers of SS with greater sensitivity (SE) and specificity (SP). FS $\geq 3, G C$, LEL and LF were only found in SS and were associated in previous studies with higher risk of lymphoma and systemic disease.

\begin{tabular}{ccccccc}
\hline & & \multicolumn{3}{c}{ Prevalence } & \multicolumn{2}{c}{ Test } \\
\hline & & SS & NSS & $\mathrm{p}$ value & Sensitivity & Specificity \\
\hline Classification criteria & Schirmer's test & $78.6 \%$ & $57.6 \%$ & $\mathrm{p}=0.019$ & 0.78 & 0.42 \\
& UWSF & $65.5 \%$ & $38.3 \%$ & $\mathrm{p}=0.004$ & 0.65 & 0.62 \\
& Anti-Ro+ & $52.7 \%$ & $6.7 \%$ & $\mathrm{p}<0.001$ & 0.53 & 0.93 \\
Non classification & FS $\geq 1$ & $66.7 \%$ & $25 \%$ & $\mathrm{p}=0.027$ & 0.67 & 0.75 \\
criteria & Anti-La+ & $18.5 \%$ & $1.8 \%$ & $\mathrm{p}=0.003$ & 0.43 & 0.87 \\
& ANA+ & $74.5 \%$ & $28.3 \%$ & $\mathrm{p}<0.001$ & 0.75 & 0.72 \\
& RF+ & $38.2 \%$ & $10.0 \%$ & $\mathrm{p}=0.001$ & 0.43 & 0.87 \\
& Scintigraphy & $49.1 \%$ & $38.3 \%$ & $\mathrm{p}=0.245$ & 0.49 & 0.62 \\
Histological & Xerostomia & $76.1 \%$ & $77.9 \%$ & $\mathrm{p}=0.663$ & 0.76 & 0.2 \\
characteristics & Xerophthalmia & $74.5 \%$ & $83.8 \%$ & $\mathrm{p}=0.302$ & 0.74 & 0.16 \\
& LI & $92.2 \%$ & $27.5 \%$ & $\mathrm{p}<0.001$ & 0.9 & 0.78 \\
& FLS & $81.8 \%$ & $6.7 \%$ & $\mathrm{p}<0.001$ & 0.82 & 0.93 \\
& GA & $75.5 \%$ & $50.9 \%$ & $\mathrm{p}=0.010$ & 0.76 & 0.49 \\
& GC & $2.0 \%$ & - & $\mathrm{p}=0.310$ & 0.02 & 1.00 \\
& LEL & $12.2 \%$ & - & $\mathrm{p}=0.011$ & 0.11 & 1.00 \\
& LF & $4.1 \%$ & - & $\mathrm{p}=0.153$ & 0.04 & 1.00 \\
\hline
\end{tabular}

Conclusion: SS is a heterogeneous disease that requires a comprehensive clinical, serological, functional and histological evaluation. MSGB is a simple, safe, repeatable procedure that provides enormous information. It was the single parameter that best correlated with SS and allowed the diagnosis of seronegative
SS. In summary, the use of MSGB is essential not only for the differential diagnosis of sicca syndrome but also as a prognostic marker for SS.

REFERENCES: :

[1] Bautista-Vargas et al. Autoimmun Rev. 2020 Dec;19(12):102690.

Disclosure of Interests: None declared

DOI: 10.1136/annrheumdis-2021-eular.3251

$\mathrm{AB} 0334$

THE FIRST 1000 DAYS OF LIFE AND REPRODUCTIVE DISORDERS IN WOMAN WITH RHEUMATIC DISEASE (RDS)

M. Orlandi ${ }^{1}$, S. Vannuccini ${ }^{2}$, K. El Aoufy ${ }^{1}$, M. R. Melis ${ }^{1}$, G. Lepri ${ }^{1}$, S. BellandoRandone $^{1}$, S. Guiducci ${ }^{1}$, M. Matucci-Cerinic ${ }^{1}$, F. Petraglia ${ }^{2} .{ }^{1}$ University of Florence, Department of Experimental and Clinical Medicine, Florence, Italy; ${ }^{2}$ Obstetrics and Gynecology, AOU Careggi, Department of Maternity and Infancy, Florence, Italy

Background: Gynaecological problems are often ignored by rheumatologist and have a negative impact on quality of life of RDs patients.

Objectives: The aim of this study was to describe gynaecological, reproductive and sexual problems in premenopausal woman with RDs.

Methods: A monocentric, cross-sectional observational study was conducted in the Rheumatology Department of Careggi Hospital in Florence. Inclusion criteria: female gender, premenopausal age (and $\geq 18$ years old), diagnosis of rheumatic diseases. All patients have been investigated about gynaecological anamnesis and symptoms and subjected to a self-administered validated questionnaire.

Results: From May 4 th to November 30th, 2020, 200 patients were enrolled (mean age $39.1 \pm 8.7$ years $(M \pm S D)$ ): $58 \%$ arthritis, $40 \%$ connective tissue disease and $1.5 \%$ systemic vasculitis. In the history, spontaneous, full-term birth in $91 \%$ and $93 \%$ of patients, respectively, was observed and pre-term birth was reported in $8.1 \%$. $63 \%$ of patients were breastfed. In family history, menorrhagia, dysmenorrhea, or chronic pelvic pain were reported in $59 \%, 55$ and $7 \%$ of patients, respectively. The first menstruation was at $12.3 \pm 2.0$ years $(M \pm D S)$ and mostly woman reported menstrual disorders during adolescence (56\% experienced dysmenorrhea and 52\% menorrhagia). Menstrual disorders and abnormal bleeding were frequently reported also in adulthood: $71 \%$ had dysmenorrhea, $38 \%$ heavy menstrual cycles and $9 \%$ metrorrhagia. Moreover, $26 \%$ of patients referred non- menstrual pelvic pain, $19 \%$ urinary pain and $18 \%$ pain during defecation. Vaginal symptoms were frequently reported: $36 \%$ of patients referred vaginal dryness, $29 \%$ burning, $19 \%$ recurrent vaginal infections and dyspareunia in $39 \%$ of patients. Uterine fibroma was present in $23 \%$ and endometriosis in $10 \%$ of patients. Fertility problems were reported by $10 \%$ of patients in a time frame of $7.5 \pm 6.4$ years and $30 \%$ of patients experienced at least one miscarriage; otherwise, $56 \%$ of patients have had at least one full-term pregnancy.

Conclusion: RDs patients show a high prevalence of various gynaecological problems affecting their quality of life. The management of female RDs patients is a challenge for the clinician and should include an accurate evaluation of the gynaecological aspects (menstruation, fertility, maternity, sexuality) as well as a multidisciplinary teamwork (rheumatologist and gynaecologists)

\section{REFERENCES:}

[1] Critchley H., Babayev E., Bulun E., et al. Menstruation: Science and society I Elsevier Enhanced Reader. (s.d.). https://doi.org/10.1016/j. American Journal of Obstetrics \& Gynecology 2020.06.004

[2] Østensen M, Andreoli L, Brucato A,et al. State of the art: Reproduction and pregnancy in rheumatic diseases. Autoimmun Rev. 2015 May;14(5):376-86. doi: 10.1016/j.autrev.2014.12.011. Epub 2014 Dec 30. PMID: 25555818

[3] Marder W, Johnson TRB. Rheumatic diseases and maternal-fetal medicine. Best Pract Res Clin Obstet Gynaecol. 2020 Apr;64:1-2. doi: 10.1016/j. bpobgyn.2019.11.007. Epub 2019 Dec 17. PMID: 31983554.

[4] Sammaritano LR, Bermas BL, Chakravarty EE,et al. 2020 American College of Rheumatology Guideline for the Management of Reproductive Health in Rheumatic and Musculoskeletal Diseases. Arthritis Rheumatol. 2020 Apr;72(4):529-556. doi: 10.1002/art.41191. Epub 2020 Feb 23. PMID 32090480.

Disclosure of Interests: None declared

DOI: 10.1136/annrheumdis-2021-eular.3282

$\mathrm{AB} 0335$

SURVIVAL ASSESSMENT IN PATIENTS WITH SLE AND PULMONARY MANIFESTATIONS IN A COLOMBIAN COHORT WITH 2-YEAR FOLLOW-UP

S. Herrera $^{1}$, J. C. Diaz-Coronado ${ }^{1,2}$, S. Monsalve ${ }^{2}$, S. Guerra-Zarama ${ }^{2}$, M. F. Saavedra Chacón ${ }^{2}$, J. Barbosa ${ }^{2}$, J. D. Serna Giraldo², J. D. Lopez ${ }^{2}$, J. M. Gutiérrez ${ }^{2}$, T. Vega ${ }^{2}$, D. Orozco ${ }^{2}$, D. Ocampo ${ }^{2}$, N. Zuluaga ${ }^{2}$, D. HernandezParra ${ }^{1}$, D. Rojas-Gualdrón ${ }^{3}$, R. Pineda.Tamayo ${ }^{1}$. ${ }^{1}$ Artmedica, Clinical Information Group, Medellín, Colombia; ${ }^{2}$ CES University, Department of Internal Medicine, Medellín, Colombia; ${ }^{3}$ CES University, Facultad de medicina, Medellín, Colombia 